\title{
C-17 SEMI-AUTOMATIC DETECTION OF SUBSURFACE SEISMIC BODIES OF RELEVANT STRATIGRAPHIC INTEREST
}

\author{
'Eni SpA Agip Division, Technical Software Development Department, \\ PO Box 12069, 20100 Milan, Italy \\ 'Eni SpA Agip Division
}

\section{Summary}

Extensive 3D seismic volumes from around the world have started to show geometry and facies textures of geobodies, which traditionally interpreted through conventional $2 \mathrm{D}$ vertical sections, following a time-consuming seismic stratigraphic approach. This method is too labor-intensive and error-prone to be cost-effective.

This paper will describe a methodology for the semi-automatic identification of seismic 3D geobodies using single or multiple attribute approaches.

Two different approaches have been studied to provide a methodology for a classification of seismic objects (single or multiple seismic reflections) through the analysis of seismic attributes. The operations of single-attribute approach, like segmentation and threshold cutoffs, are designed to generate a facies volume. The multi-attribute approach makes a classification based on the analysis of a set of cross-plots of couples of attributes; the methodology allows the generation of facies volumes through the definition of "polygons" on those cross-plots which are more suitable for identifying interesting $3 \mathrm{D}$ seismic objects. The last step of the methodology provides the extraction of the surface enveloping the classified seismic objects. In this paper we present the usage of unconventional seismic attributes, but in general the same methodology may be used with any type of seismic attributes.

\section{Introduction}

Multi-attribute techniques have become popular in recent years and are used both for quantitative and qualitative seismic interpretation [1]. In this paper we propose the use of a new technique for semi-automatic seismic 3D geobody detection that allows a pre-screening of big seismic data sets. The methodology is innovative for two main reasons:

- the attributes used for seismic object identification are based on the analysis of both seismic textures and statistical properties of seismic data;

- the multi-attribute approach allows the use of a supervised classification in a multi variable domain.

Seismic object detection starts from the 2D interpretation of a key section. The extension to 3Dobject detection is then performed by applying the results obtained in the interpretation phase to each inline of input attributes.

\section{Methodology}

The workflow, showing both single and multi attribute approaches, is described in figure 1 . The interpretation phase is performed both in single attribute segmentation and in multi cross-plot classification. This step is very important and critical because the results of the analysis are then 
used for the automatic classification of the whole volume (step of seismic geobodies definition). The last step, geometry computation, is the application of an edge detection algorithm to each ' inline of the classified volume. Geometry computation provides the coordinates of each detected shape that may be used as preliminary $3 \mathrm{D}$ surface interpretation.

\subsection{Attributes computation}

The attributes used in the analysis are based on statistical parameters and on texture characterization. The statistical attributes used are the "mean energy" and the "mean gradient" of a sub-image extracted from the key section. Attributes based on texture characterization are second order statistical parameters computed on the cooccurrence matrix, which represents the probability of occurrence between each couple of gray tones measured along the four principal directions. Second order statistical parameters are a measure of the visual characteristics of a texture $[2][3][4]$. After attribute computation the workflow follows two different paths for multi cross-plot classification and single attribute segmentation.

\subsubsection{Multiple cross-plot classification}

Multi cross-plot classification is a methodology for seismic classification based on the use of cross-plots of seismic attributes, allowing the interactive definition of "polygons" on both seismic sections and cross-plots. This innovative methodology implements a supervised classification in a multi variable domain. The definition of a "polygon" on the key section allows the selection of the relevant seismic objects: the corresponding points on the cross-plots are automatically highlighted. The definition of a polygon on selected cross-plots allows the interpreter to highlight the corresponding points on the seismic section. The methodology consists in the definition of a set of "polygons" on multi cross-plots, in order to identify all relevant seismic objects. A numeric flag is then assigned to each "polygon" as a facies label: seismic bodies labelling is a classification process that takes as input all the attribute volumes and returns as output a volume of facies. The output value is equal to a facies flag if all the corresponding points (in each cross-plot) are "captured" by the defined "polygons" (e.g. with the same flag).

\subsubsection{Single Attribute Segmentation}

Single attribute segmentation reduces the number of gray tones of seismic images to improve the automatic identification of seismic objects. Since each gray tone is spatially connected to its neighbours, in order to define a connected shape the segmentation is performed using the Markov Random Field [5] algorithm. This algorithm is based on the following assumptions:

- the value of each sample (pixel) depends only upon the values of its neighbours;

- very sharp value transitions are avoided;

- global energy'should not increase.

Each section of the attribute is segmented separately but using the statistical information of the whole seismic attribute volume. After the segmentation process, seismic geobody definition is performed setting a threshold on attribute sample values, namely the gray levels. All values less than the threshold are assigned to the background, while greater values identify the target seismic geobodies.

\subsection{Geometry computation}

The last step of the methodology uses as input the facies volume and produces as output an automatic identification of the external geobody geometry. The algorithm used for the geometry computation is based on an edge detection operation performed on each section of the facies 
volume. The coordinates of the external geometry envelope are available as output and can be used to support the following interpretive steps and can be visualized in 3D.

\section{Results}

The multi cross-plot methodology has been applied for the identification of a channel. Figure 3 shows on the seismic section, the key stratigraphic feature used in the interpretation phase. After the computation of statistical and texture attributes, "polygons" have been defined on a single cross-plot (figure 2.). The "polygon" identifies correctly the channel on the seismic section. The same figure shows also additional cross-plots and the position of all selected samples. The result of the classification and the subsequent geometry computation are shown in figure 4 .

The single attribute computation has been applied to the mean energy attribute (computed using a window of 32 samples and 32 traces). Figure 5 shows the result of the application of a cut-off on the segmented attribute, followed by geometry computation. In both cases the surfaces contain the facies associated to the channel as desired. Figure 6 shows the result of 3D-object identification obtained with multi attribute computation.

\section{Conclusion}

The presented methodology has improved the identification of seismic 3D-objects and provides the principles for a multi attribute supervised classification. The methodology is not oriented to the detection of particular seismic objects but, being based on texture analysis, provides a general seismic facies framework that may be used for the automatic detection of differently shaped geobodies of stratigraphic interest.

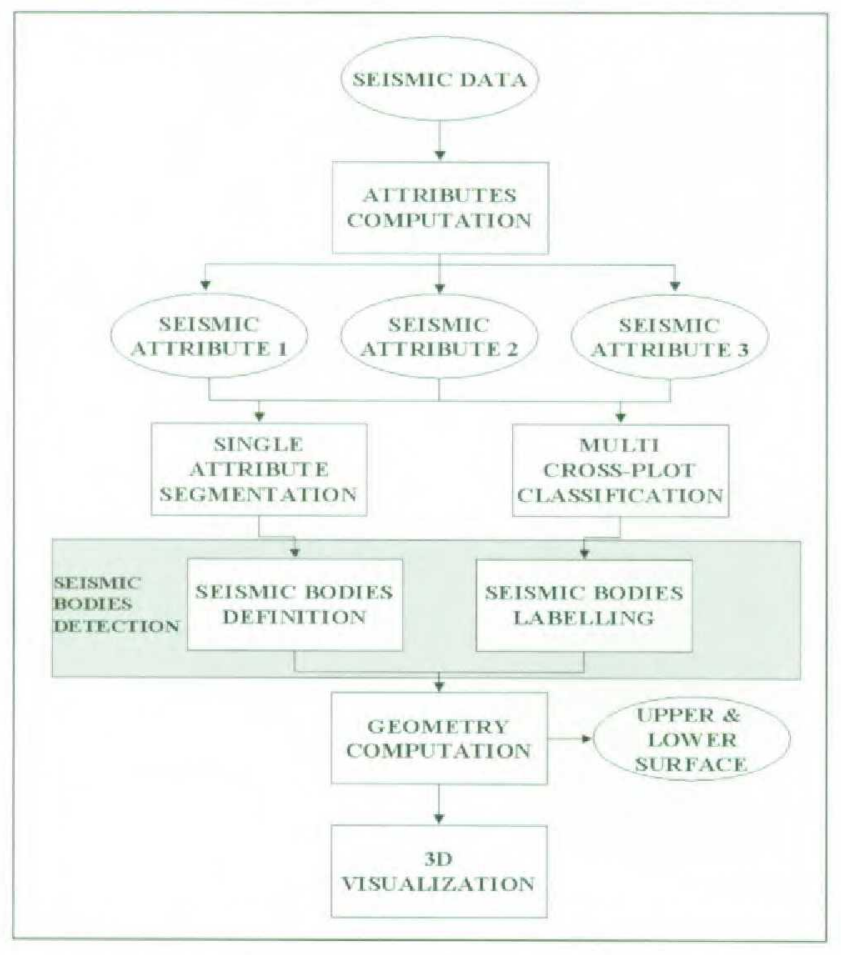

Figure 1. Workflow of the methodology.

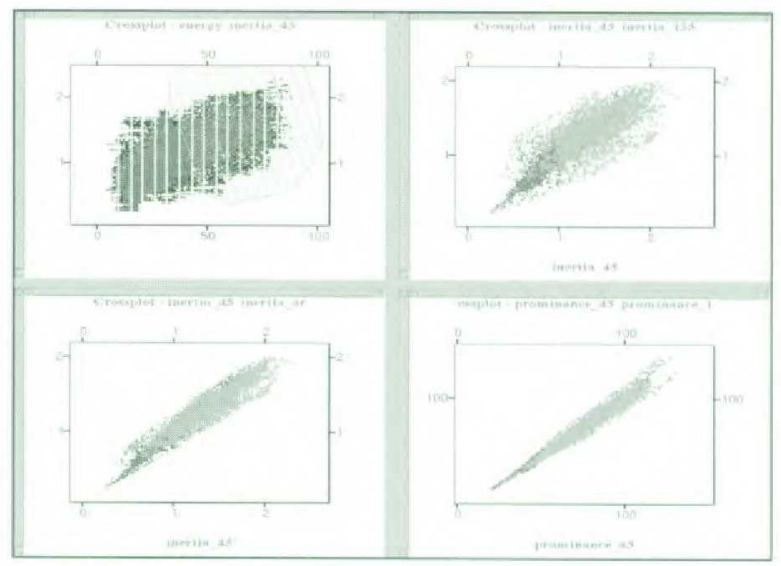

Figure 2. Multi cross-plot classification.

\section{References}

[1] M. Fervari, C. Tarchiani, L. Ferri, M. Piantanida' (1999). "An advanced approach to seismic facies classification and calibration”. EAGE 1999, Elsinky. 
[2] Haralick, R.M. (1979). "Statistical and Structural Approaches to Texture", Proc. Of the IEEE, 6,5 .

[3] McLean, G.F. (1993). "Vectro Quantization for Texture Classification", IEEE Transaction on Systems, Man and Cybernetics, 23, 3.

[4] M.T. Galli, M. Ponzi, A. Riva (1995) "Exploting neural computing: a valuable tool for today's data interpretation needs". AI Petro 1995.

[5] S.Z. Li, "Markov Random Field Modeling in Computer Vision", Springer-Verlag, 1995.

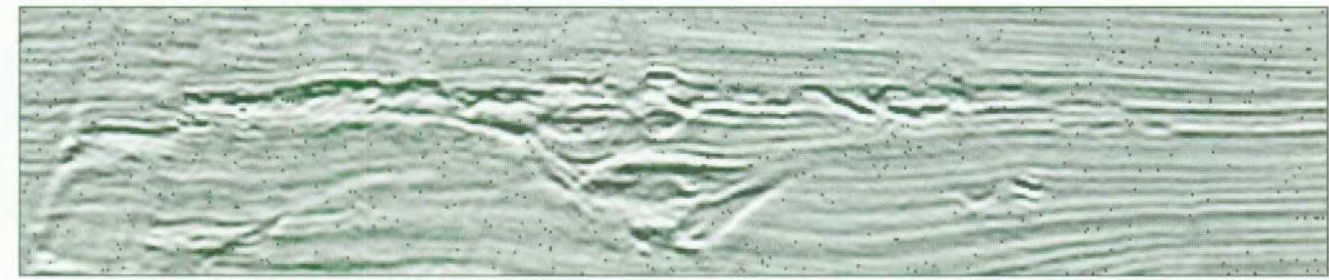

Figure 3. Seismic section used in the interpretation phase.

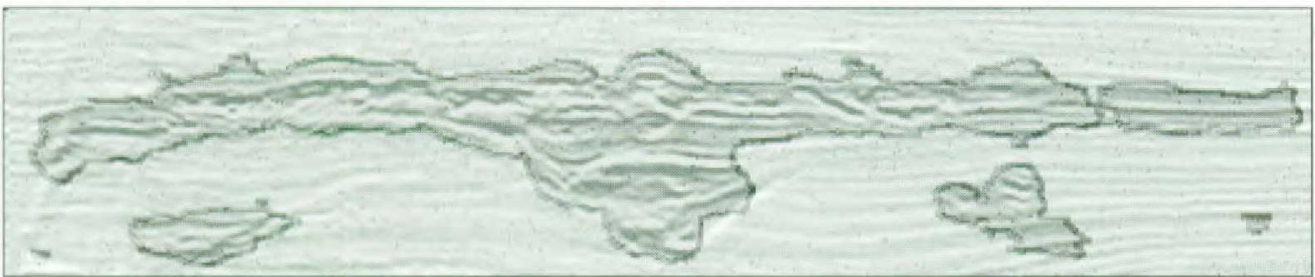

Figure 4. Classification and geometry computation result.

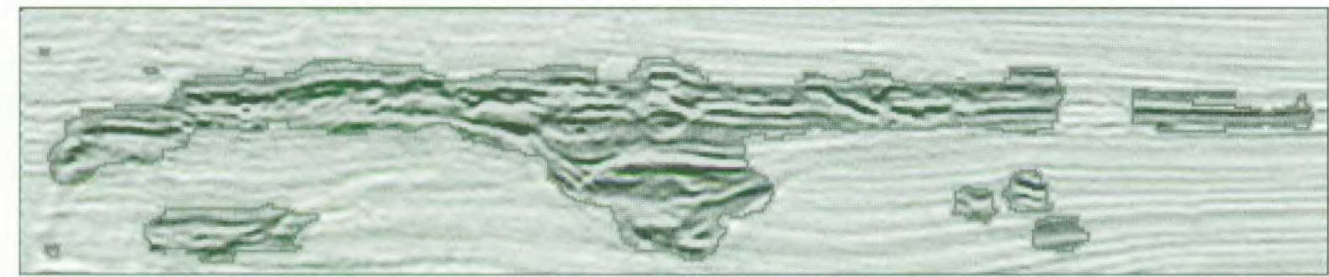

Figure 5. Segmentation, cut-off and geometry computation result.

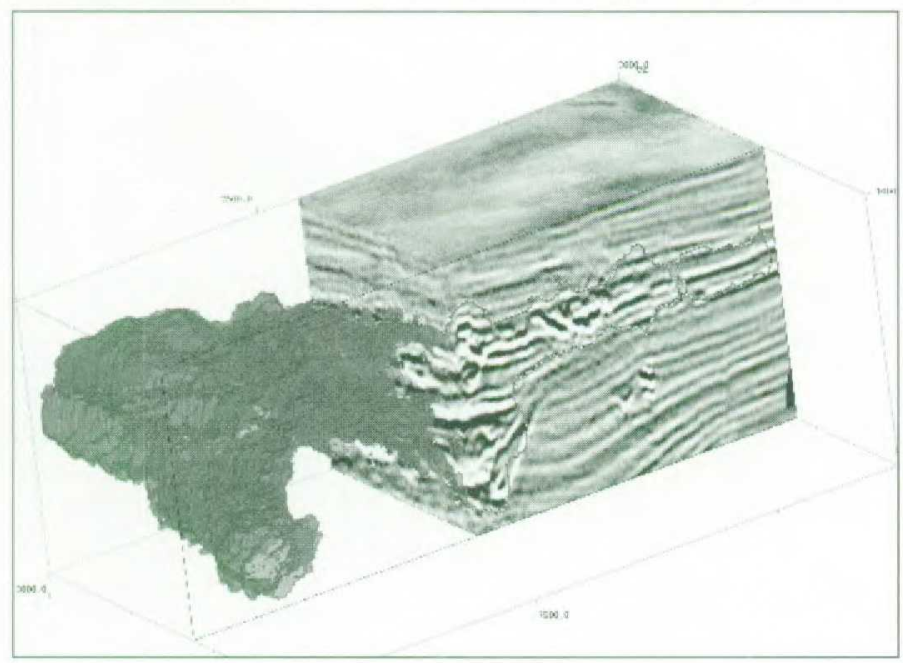

Figure 6. 3D Facies volume. 
Sidescan sonar and sub-bottom profiler technology: techniques for enhancing deep water reservoir visualization in Modern depositional environments

Bryan Cronin and Andrew Hurst

Department of Geology and Petroleum Geology, University of Aberdeen

Validation of subsurface reservoir models from 3-D seismic extractions needs integration of Modern and Ancient analogue data. Increasing resolution of seismic data and the routine use of inversion techniques, amplitude and other extractions, have increased the overlap in scale between subsurface and analogue data, where previously this overlap was quite considerable. The use of high-resolution, usually deep-towed, sidescan sonar data (showing planform expressions of Modern depositional environments) in combination with sub-bottom profiler data (showing cross-sectional geometries of the same systems), and locally in combination with ground-truthed sedimentological data (cores) has only recently been a routine way of examining Modern systems by oceanographers. This is partly due to the recent improvements in SSS technology, partly due to poor sediment recovery in sandy depositional environments, partly due to difficulties in operating at such depths, and partly due to the lack of funding enthusiasm of the hydrocarbon sector for looking at Modern systems. The reasoning for the latter was principally due to the suspicion that there is a lack of analogy between Modern, largely 'empty' channels and filled subsurface ones, but also because the lack of overlap in scale between the two types of data. Present enthusiasm for this type of work is driven by the removal of all of these obstacles, and to the discovery of so many giant accumulations of hydrocarbons in the South Atlantic and deep Gulf of Mexico.

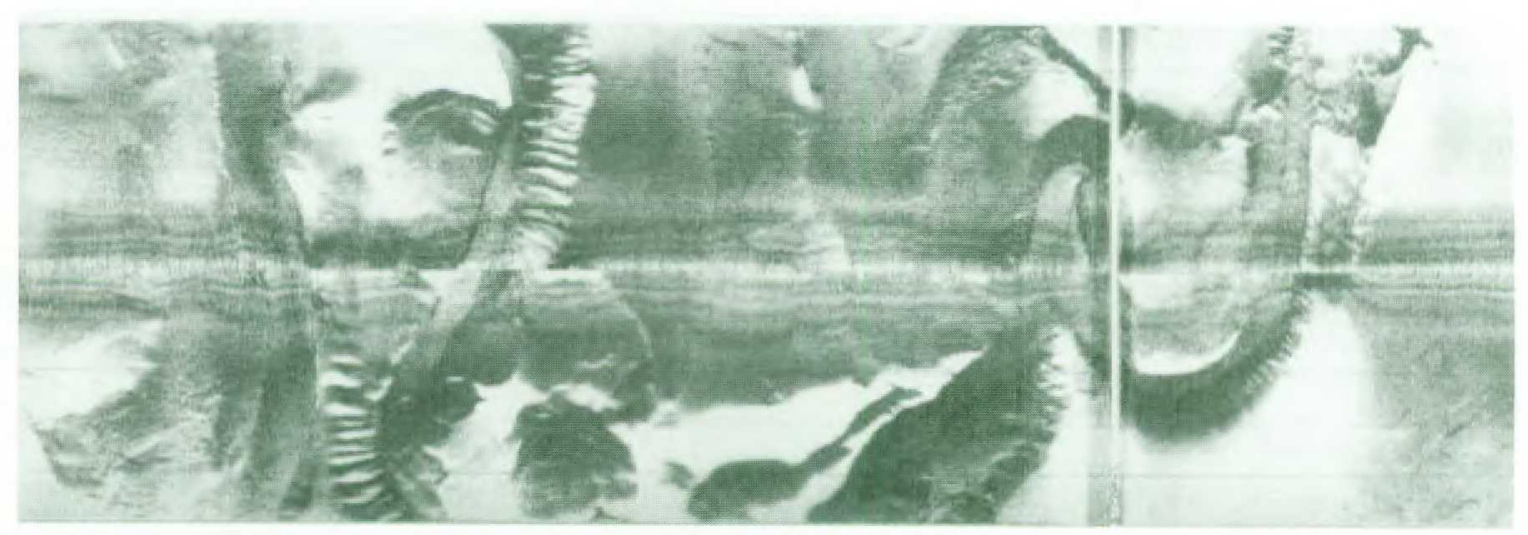

Interpretation of Modern data needs the skills of ocean-going scientists, as SSS images in particular are now so spectacular that one is tempted to interpret them as optical images of the sea floor rather than acoustic responses of the shallow subsurface and sea floor to the sonar frequencies used in different surveys. This is not too dissimilar to the problems encountered in interpreting 3-D seismic cubes as 'snapshots' of time rather than interpreting elements within a cube of sediment which may have spatial, but no temporal association. Ideally, significant validation of sand distribution in deep-water clastic systems, and the interpretation of realistic sand body geometry, needs the combined expertise of oceanographers, geologists, and subsurface interpreters. This presentation gives a series of examples of how one can use 
Modern SSS and SBP technology, to improve interpretation of 3-D seismic datasets from analogous systems.

Data from parts of spectacular sediment transfer systems on the West African margin, particularly deepwater canyons, reveal very unexpected distribution of sand and conglomerate bodies within parts of the canyon fills, and laterally equivalent to them. These volumes of coarse sediment are significant, but can their location, reservoir quality and connectivity be predicted using analogue data?
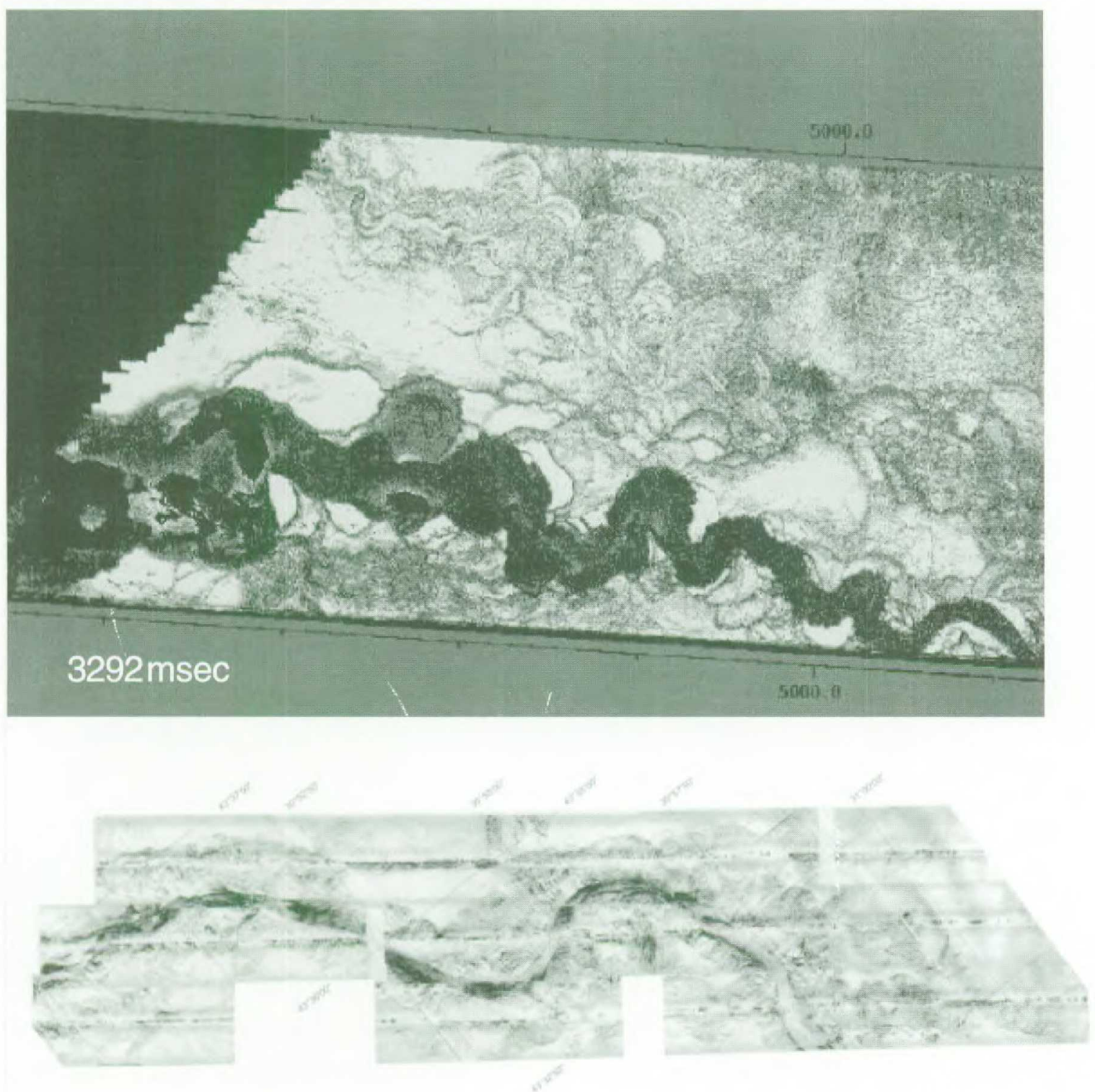

A series of Modern Canyons, imaged using Russian (MAK-1 and MAK-2) deep-towed sidescan sonar data, are presented to illustrate analogous parts of these systems. Are sinuous elements within deep-water canyons sinuous deep-water channels or slump-enhanced bends in channel courses with much lower sinuosity? What significance does slump body and debris flow have on the control on overlying sand body geometry? A second series of canyons, imaged off Western Ireland (Porcupine) and NW Shetlands 
(offshore U.K.) using the same technology but cored more extensively, was collected during the summer of 2000. These new data are combined with the other data (collected during subsequent cruises since 1991) to try and resolve the more enigmatic shapes imaged on the 3-D seismic.

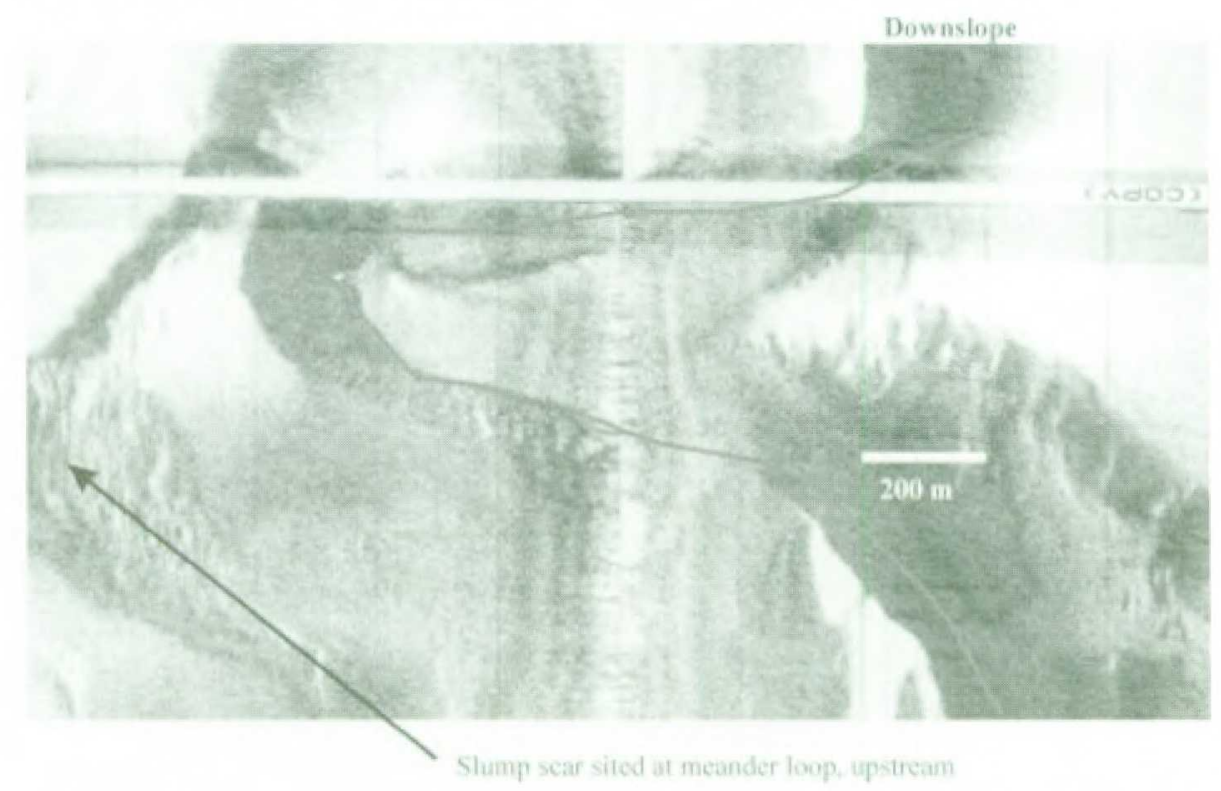

CRONIN, B.T., KENYON, N.H., WOODSIDE, J.M., IVANOV, M., den BEZEMER, T., MILLINGTON, J., van der WAL, A., and LIMONOV, A. (1995) Views of the Andarax submarine canyon: a meandering system on an active tectonic margin. In: K.T. Pickering, N. Hiscott, R. Smith and N.H. Kenyon, (eds.). Atlas of deep water environments - architectural style in turbidite systenaqman and Hall, London. 8488.

CRONIN, B.T. (1996). Modelling turbidite hydrocarbon reservoirs: how best to use modern geophysical and ancient outcrop data. Abstracts, Sedimentary Basins of the Mediterranean and Black Seas, UNESCOIOC-ESF 4 Post-Cruise Meetng, Moscow, ${ }^{\text {th }}$ ganuary - th February.

CRONIN, B.T. and HURST, A. (1998a). Generic components of leveed deep-water channels. Abstracts, Modern and Ancient Analogues: uses and abuses in the subsurface. Meeting of the Petroleum Group of the Geological Society, September 22-23, Aberdeen. Convenors A. Hurst and B. Cronin. p.12-13.

CRONIN, B.T. and HURST, A. (1998b). Generic components of deep-water clastics - building blocks for the subsurface from modern and ancient analogue data. Abstracts, AAPG Annual Convention, Rio de Janeiro, Brazil, November 8-11.

HURST, A., CRONIN, B.T. and HARTLEY, A.J. (2000). Reservoir modelling sand-rich deep-water clastics: the necessity of down-scalirfetroleum Geoscienc6, No. 1, p.67-76.

Contact:cronin@abdn.ac.uk

Or www.TurbiditeReservoir.com/ 